\title{
Spatial structure in invasive Alliaria petiolata reflects restricted seed dispersal
}

Post-print/Accepted manuscript

Shekhar R. Biswas

Helene H. Wagner

Biswas, S.R. \& Wagner, H.H. Biol Invasions (2015) 17: 3211. doi:10.1007/s10530-015-0946-8

The final publication is available at Springer via http://dx.doi.org/10.1007/s10530-015-0946-8

\section{HOW TO CITE TSPACE ITEMS}

Always cite the published version, so the author(s) will receive recognition through services that track citation counts, e.g. Scopus. If you need to cite the page number of the TSpace version (original manuscript or accepted manuscript) because you cannot access the published version, then cite the TSpace version in addition to the published version using the permanent URI (handle) found on the record page. 
Biswas \& Wagner: Spatial structure of A. petiolata

2 Spatial structure in invasive Alliaria petiolata reflects restricted seed dispersal

3 Shekhar R. Biswas ${ }^{1}$ and Helene H. Wagner

4 Department of Ecology and Evolutionary Biology, University of Toronto, 3359 Mississauga

5 Road North, Mississauga, Ontario, Canada L5L1C6

6

7

8 Manuscript word count (abstract to end of figure legends): 7472

9 Number of figures: 3

10 Number of Tables: 3

11 Supporting material: 2

${ }^{1}$ E-mail: shekhar.forest@gmail.com 


\section{Abstract}

13 Identification of processes that shape the spatial structure of invasive species has

14 important implications for understanding population regulation. In invasive Alliaria petiolata we

15 quantified (i) spatial scale of seed dispersal under field conditions, (ii) spatial structure of rosette

16 and adult density and (iii) the relative importance of environmental filtering, propagule pressure

17 and adult-rosette interactions in shaping rosette and adult density. We conducted a seed dispersal

18 experiment under field conditions; and in a three year field survey we measured quadrat-level

19 rosette and adult density, adult seed production and soil moisture and light along transects in

20 three A. petiolata populations at Koffler Scientific Reserve in Southern Ontario, Canada.

21 Propagule pressure was estimated based on quadrat-level seed production and neighbourhood

22 seed production. We found that seed dispersal of $A$. petiolata followed a lognormal distribution

23 with a mean dispersal distance of $1.82 \mathrm{~m}$, and that spatial structure in both adults (Moran's $I$ :

$240.30-0.56)$ and rosettes $(0.48-0.57)$ was significant up to $2 \mathrm{~m}$. Propagule pressure and adult-

25 rosette interactions were significant processes associated with rosette density, whereas propagule

26 pressure was the most important process associated with adult density. However, due to the

27 observational nature of the data, it is difficult to determine whether the observed negative

28 association between adult and rosette density is related to competition or to temporal variation in

29 density-dependent seed production. Overall, we conclude that spatially restricted seed dispersal

30 is the most important factor underlying this species' patchy distributions.

33 Key Words: Alliaria petiolata; seed dispersal; spatial autocorrelation; spatial processes 


\section{Biswas \& Wagner: Spatial structure of A. petiolata}

\section{Introduction}

35 In natural landscapes, many invasive species show patchy spatial distributions. Since

36 processes shaping the dynamics of ecological populations often leave their signatures in the

37 spatial structure of populations and communities (Powell 1990; Seabloom et al. 2005), analysis

38 of spatial structure may offer useful insights into the mechanisms of species' spatial organization

39 (Fortin and Dale 2005; McIntyre and Fajardo 2009). Such knowledge is crucial to devise

40 appropriate management strategies for invasive populations. However, identifying important

41 processes creating spatial structure in ecological populations may be challenging because

42 numerous processes interactively shape ecological populations and we rarely know about all

43 processes (Fortin et al. 2012). Furthermore, a single process may create varying spatial structure

44 (Pielou 1960; Powell 1990) and different processes may create similar spatial structure (Fortin

45 and Dale 2005; Malkinson and Jeltsch 2007; Dray et al. 2012).

46 One way to deal with these challenges is to simultaneously quantify the relevant

47 processes as identified by theories on spatial organization, such as metapopulation theory or the

48 metacommunity concept. The latter emphasizes three key process: $(i)$ environmental filtering, $(i i)$

49 dispersal and (iii) species interactions (Gilpin and Hanski 1991; Leibold et al. 2004; Biswas and

50 Wagner 2012). These three processes may be a good starting point (Legendre 1993; Dorman et

51 al. 2007), whereas any remaining residual spatial structure after accounting for these processes

52 may point towards additional important processes (Wagner and Fortin 2005; Dray et al. 2012).

53 Since lack of a unique signature of each process makes the task of inferring processes

54 from spatial structure challenging (McIntyre and Fajardo 2009), attempts should to be made to

55 quantify them directly if possible. While many studies quantify environmental conditions and

56 biotic interactions directly, dispersal is often either approximated by geographic distance or

57 introduced as a post-study explanation for residual spatial structure (Cottenie 2005). However, 


\section{Biswas \& Wagner: Spatial structure of A. petiolata}

58 dispersal is a central process of species spatial organization (Nathan and Muller-Landau 2000;

59 Nathan et al. 2000). In real landscapes, species dispersal may be a highly complex process

60 (Biswas and Wagner 2012), so that approximation of species dispersal based on variance

61 explained by 'space' as commonly done (Cottenie 2005) may be insufficient. Empirical

62 assessment of seed production, dispersal and resulting propagule pressure is important to

63 understand species' spatial organization (Nathan and Muller-Landau 2000; Colbert 2001). This is

64 even more important for invasive species, as propagule pressure is a major factor underlying

65 successful invasion (Lockwood et al. 2005; Colautti et al. 2006). Yet, there is a paucity of studies

66 that measured dispersal and resulting propagule pressure directly together with other processes

67 (Nathan and Muller-Landau 2000; Colbert et al. 2001; Colautti et al. 2006).

68 Alliaria petiolata (M. Bieb.) Cavara and Grande, an invasive forb in North America, is

69 ideally suited for studying the relative importance of processes because this species generally

70 occurs in patches (see Online Resource 1), and the processes shaping population dynamics of

71 this biennial species are relatively well known (e.g., Davis et al. 2006). In forest understory, $A$.

72 petiolata can be very dominant (Luken and Thieret 1997; often covering $80-100 \%$ of a quadrat),

73 so that interspecific interactions may have negligible effects on the dynamics of $A$. petiolata

74 (Biswas and Wagner 2014). While considerable research has been conducted on autecology and

75 population dynamics of $A$. petiolata (see review by Rodgers et al. 2008), its dispersal ability and

76 resulting propagule pressure, as well as the relative importance of processes shaping the spatial

77 distribution of adults and rosettes density, are still poorly understood.

78 In this study we experimentally assessed the spatial scale of seed dispersal under natural

79 field conditions, and analyzed three-year permanent plot data on adult and rosette densities to

80 examine whether the patchiness in adult and rosette densities corresponds to the spatial scale of

81 seed dispersal and to assess the relative importance of processes shaping adult and rosette 
82 densities by relating density data to quadrat-level environmental site conditions (environmental

83 filtering), life-stage interactions (adults vs. rosette densities), and propagule pressure. We thus

84 asked three questions: (i) What is the spatial scale of seed dispersal in A. petiolata? (ii) What are

85 the degree and spatial extent of spatial structure of adult and rosette density in A. petiolata? (iii)

86 What are the effects of environmental factors, propagule pressure and life-stage interactions on

87 adult and rosette density in A. petiolata? We hypothesized that: (i) A. petiolata is characterized

88 by short dispersal, as its seeds lack morphological adaptation for seed dispersal and are thus

89 expected to disperse through gravity, potentially followed by secondary dispersal through animal

90 vectors. (ii) Spatial structure in rosettes is characterized by higher intensity of spatial

91 autocorrelation than the spatial structure in adults. We expect this because short range dispersal

92 creates patchiness in rosettes, whereas density-dependent effects are expected to reduce

93 patchiness in adults (Powell 1990; Winterer et al. 2005). (iii) Propagule pressure and biotic

94 interactions have a larger effect on the density of both adults and rosettes than environmental

95 filtering, because $A$. petiolata occurs in a wide range of environmental site conditions (Cavers et

96 al. 1979), which suggests a weak role of environmental filtering (Winterer et al. 2005).

\section{Methods}

99 Study species and site

100 Alliaria petiolata is a Eurasian native and an invasive forb in North America (Rodgers et

101 al. 2008). The species occurs in diverse habitat types such as in forest understory, forest edges,

102 along roadside verges, in open grasslands, and along stream bank riparian areas (Cavers et al.

103 1979; Meekins and McCarthy 2001). Alliaria petiolata is a biennial species with two distinct life

104 stages: first year rosettes and second year adults. Seeds germinate in early spring and develop 


\section{Biswas \& Wagner: Spatial structure of A. petiolata}

105 into rosettes, which grow during summer and fall and survive winters under snow cover with

106 some green leaves (Cavers et al. 1979).

107 In the second year after spring snowmelt, A. petiolata quickly grows stalks and produces

108 flowers, which may self-pollinate or be pollinated by generalist pollinators such as solitary bees,

109 honey bees and syrphid flies (Cruden et al. 1996; Rodgers et al. 2008). Alliaria petiolata then

110 produces siliques (seed capsules), each containing 10-20 seeds of 2.5-3 mm length (Cavers et al.

111 1979). After release of seeds in June - September, which generally occurs through bursting of

112 siliques, adults die (Anderson et al. 1996). Alliaria petiolata does not possess any specialized

113 dispersal mechanism, and most seeds disperse by gravity. Yet, some seeds may disperse further

114 by wind, deer, small mammals, water current and humans (Cavers et al. 1979; Evans et al. 2012).

115 It is generally assumed that most $A$. petiolata seeds fall within a few meters of the mother plant

116 (Rodgers et al. 2008). Approximately 5 - 70\% of seeds germinate in the next spring and develop

117 new rosettes; the remaining seeds stay viable in the seed bank up to $5-10$ years (Cavers et al.

118 1979, Evans et al. 2012).

119 Our study site was the Koffler Scientific Reserve at Jokers Hill (KSR), a University of

120 Toronto field site near King City, Ontario, Canada. Here $A$. petiolata occurs in mesic forest

121 understory, in moist grasslands and along trails. Detailed topographic, edaphic and vegetation

122 maps of the study area are available at www.ksr.utoronto.ca. The first record of $A$. petiolata in

123 Canada by J. Fletcher dates back to 1879 (Cavers et al. 1979). The history of $A$. petiolata

124 invasion at KSR is not well documented, but is estimated to be at least 20-25 years old (Biswas

125 and Wagner 2014). 
134 Our choice of a $10 \mathrm{~m}$ radius was driven by a plan to place seed traps up to $4 \mathrm{~m}$ from the point

135 source with a buffer of $6 \mathrm{~m}$. We considered $4 \mathrm{~m}$ for seed trap placement because we expected

136 that seeds would stay within few meters (Rodgers et al. 2008). Outside each $10 \mathrm{~m}$ experimental

137 zone, we flattened all standing adults of $A$. petiolata within the next 2-3 $\mathrm{m}$ to the ground. 144 steel mesh (mesh window net) so that water could pass through but seeds not. Each seed trap was 145 established in the field as follows: the base was inserted fully into the ground using a hammer, 146 the seed holder was then placed on the base, and finally a cover was placed on the top of the seed 147 holder (Fig. 1).

Seed traps were manufactured in-house (Mechanical Department; University of Toronto, Mississauga). Each seed trap had an area of $78.54 \mathrm{~cm}^{2}$ and consisted of three parts: the base, the seed holder and the cover (Fig. 1). The base $(3 \mathrm{~cm}$ height) offers a stable point to place the seed holder ( $6 \mathrm{~cm}$ height), and a 0.5 inch wire mesh cover protects seeds from predation by small animals. Both base and seed holders were built from poly-vinyl-chloride (PVC) pipe, which was circular in shape with a diameter of $10 \mathrm{~cm}$. The bottom of each seed holder was netted with fine

In July 2010, when most adults had developed siliques and there was little indication of developing further flowers or siliques, we clipped any new siliques in the non-source plants. We then counted the number of siliques for each point source (average: 102.6; range: $82-128$ ). We 


\section{Biswas \& Wagner: Spatial structure of A. petiolata}

151 did not open siliques of the source plant but opened five siliques from nearby non-source plants

152 and counted the number of seeds per silique (average: 15.796). From the product of the number

153 of siliques at each point source (2-3 source plants) and average number of seeds per silique, we

154 estimated available seeds at each point source. The average number of seeds at each point source

$155(N=5)$ was estimated as 1617 with a range of $1312-2004$. We then placed 55 seed traps around

156 each point source, starting from 0.5 meters and extending up to four meters, with an interval of

1570.5 meters, so that seed traps were placed at: $0.5,1,1.5,2,2.5,3,3.5$ and 4 meters away from a

158 point source. The area around each point source was divided into four quadrants and seed traps

159 were placed approximately equally spaced within each quadrant (Fig. 1). Because the probability

160 of seed travel decreases with increasing distance from the seed source, we increased the number

161 of seed traps at each interval with increasing distance (Bullock and Clarke 2000).

162 In late October 2010, when seeds from source points were dispersed, we collected seeds

163 from each trap and counted them in the laboratory. During seed collection from the traps, we

164 noticed minor disturbance: several traps were displaced ( $2-13$ per site $)$ and several contained

165 full siliques with stalks that were likely dispersed by animals; we excluded those traps from 166 analysis.

168 Field survey

169 In August 2009, we established transects of permanent plots and collected demographic

170 and environmental information in three comparable populations of $A$. petiolata occurring in

171 forest understory at KSR. For each field population, we laid out four perpendicular radial

172 transects of contiguous $1 \mathrm{~m}^{2}$ quadrats extending from the center to the edge of the $A$. petiolata

173 patch (see Online Resource 1). The number of quadrats in each transect was variable (range: 12

174 to 25 ; on average 17 quadrats per transect). In each quadrat $(N=196)$, we collected data on $(i)$ 


\section{Biswas \& Wagner: Spatial structure of A. petiolata}

175 number of adults $\left(A_{t}\right)$, (ii) number of rosettes $\left(R_{t}\right)$ and (iii) mean seed production per adult $\left(S_{t}\right)$,

176 for three years (August 2009, June 2010 and 2011). To quantify the number of seeds per adult

177 plant, we counted the number of siliques ( $\left.n_{\text {siliques }}\right)$ in each of three (2010) or five (2009) randomly

178 selected adults in each quadrat (if a quadrat had fewer individuals, we measured all); we opened

179 three randomly selected siliques from each plant to count the number of seeds per silique $\left(n_{\text {seed }}\right)$.

180 Quadrat-level seed production $(q S)$ was quantified for each quadrat as the product of its average

181 number of seeds per silique, its average number of siliques per plant, and its observed number of

182 adults (i.e., $q S=n_{\text {seed }} \times n_{\text {siliques }} \times A_{t}$ ).

183 As environmental variables, we measured (in August for the year 2009 and in June for

184 years 2010 and 2011) leaf area index (LAI) as a proxy for light, and soil moisture content $(M)$

185 annually for each quadrat $(N=196)$. For soil moisture, we took three measurements (using a

186 TDR probe) within each quadrat and averaged them to represent a quadrat (median 19\%, range:

$1877-30 \%)$. All soil moisture measurements were taken within a period of three days without any

188 rainfall event seven days prior to sampling days. For light, we took a canopy image at breast

189 height (using a Digital Plant Canopy Imager CI-110) in each quadrat and analyzed the image for

190 leaf area index $(L A I)$.

192 Statistical analyses

193 Quantifying the spatial scale of seed dispersal

194 Separately for each replicate point source $(N=5)$, we used the function 'fitdistr' from $\mathrm{R}$

195 library "MASS" (Venables and Ripley 2002) to fit a Weibull, a lognormal, an exponential and a

196 half normal model to the average number of seeds $\left(S_{\mathrm{d}}\right.$, rounded to the nearest integer) recovered

197 per seed trap for each distance level $d$ from the point source, where $d=\{0.5 \mathrm{~m}, 1 \mathrm{~m}, \ldots, 4 \mathrm{~m}\}$.

198 We extracted model parameter and model log-likelihood values for each point source. Based on 
199 the log-likelihood $(\ln (L))$, the number of parameters in a model $(k)$, and the number of

200 observations $\left(S=\Sigma_{\mathrm{d}} S_{\mathrm{d}}\right.$ ), we quantified $A I C c$ (Akaike Information Criterion with a correction for

201 small samples) for each model, separately for each point source as:

$$
A I C_{c}=2 k-2 \ln (L)+\frac{2 k(k+1)}{S-k-1} .
$$

204 lowest $A I C c$ for each data set (Table 1). We used the "transectHolder" function in R library

205 "spuRs" (Jones et al. 2012) to average parameters of the log-normal model across the five

206 replicates. The "transectHolder" function fits the same nominated probability density function to

207 each point source, then averages the fitted parameters across point sources (Jones et al. 2009). It

208 returns an averaged transect probability density function (transect pdf), $f_{T}(r)$ with parameters $\mu_{\mathrm{T}}$

209 and $\sigma_{\mathrm{T}}$, giving equal weight to each point source and accounting for trap size.

210 The mean displacement of a seed from a point source is given by the radial pdf, $f_{R}(r)$,

211 which accounts for the radial diffusion effect. For the log-normal model, $f_{R}(r)$ is approximated by

$212 r f_{T}(r)$, and the parameters $\mu_{\mathrm{R}}$ and $\sigma_{\mathrm{R}}$ of the radial pdf can be estimated by $\mu_{\mathrm{R}}=\mu_{\mathrm{T}}+\sigma_{\mathrm{T}}^{2}$ and $\sigma_{\mathrm{R}}=$

$213 \sigma_{\mathrm{T}}$ (Jones et al. 2009). Mean seed displacement distance was estimated by the mean of the log-

214 normal distribution, $\exp \left(\mu_{\mathrm{R}}+{\sigma_{\mathrm{R}}}^{2} / 2\right)$.

216 Quantifying spatial structure of Alliaria petiolata

217 We quantified spatial autocorrelation in $A$. petiolata density, separately for each life stage

218 and year, using Moran's spatial correlogram (Moran 1948). As implemented in the function

219 “sp.correlogram” in R library "spdep" (Bivand et al. 2012), spatial autocorrelation, $I(d)$, for each

$220 \quad \operatorname{lag}(d)$ was calculated as: 
Biswas \& Wagner: Spatial structure of A. petiolata

$$
I(d)=\frac{\frac{1}{W} \sum_{i=1}^{n} \sum_{j=1}^{n} w_{i j}\left(x_{i}-\bar{x}\right)\left(x_{j}-\bar{x}\right)}{\frac{1}{n} \sum_{i=1}^{n}\left(x_{i}-\bar{x}\right)^{2}},
$$

222 where $W$ is the number of pairs of quadrats considered in a particular lag class $d$, and $w_{i j}$ is the

223 spatial weight between observations $i$ and $j$. In defining spatial relationships (i.e., the spatial

224 weight matrix $\mathbf{W}$ ), adjacent quadrats were considered as neighbors (rooks connection; binary

225 neighbor list, weights $=$ row standardized).

226 To improve residual distribution, density data were transformed to square roots. Since

227 spatial analysis is sensitive to broader-scale patterns, all transformed variables were detrended

228 (i.e., we retained the residuals of a linear regression of each transformed variable against $\mathrm{x}$ and $\mathrm{y}$

229 coordinates of transect positions) and scaled to zero mean and unit variance, separately for each

230 population (Legendre and Legendre 1998; Dale and Fortin 2005; Wagner and Fortin 2005;

231 Schlup and Wagner 2008). Using these transformed, detrended and standardized variables, we

232 computed Moran's $I$ correlograms over nine lag classes. The number of lags was determined on

233 the basis of Sturge's rule (Legendre and Legendre 1998; Fortin et al. 2002) and kept constant

234 between populations to facilitate comparison. If the overall test for the correlogram was

235 significant, we tested statistical significance of the correlogram statistic in each lag distance

236 using progressive Bonferroni correction (Hewit et al. 1997). This procedure, where the first lag is

237 tested with $\alpha=0.05$ and subsequent lags $k$ are tested with $\alpha=0.05 / k$ if and only if all previous

238 lags were significant, is recommended for determining the extent of positive spatial

239 autocorrelation with an a priori hypothesis that patchiness would be in the smallest distance

240 classes (Legendre and Legendre 1998). 
242 Comparing importance of processes

243 We quantified each process hypothesized to shape adult and rosette densities of $A$.

244 petiolata with 1 - 2 variables measured in the field (Table 2). Based on the results from the seed

245 dispersal experiment (see below), we created a new variable to represent the seed dispersal from

246 neighboring quadrats $(n b S)$ as the average of seeds from adjacent quadrats. We did not include

247 second neighbor quadrats in the estimation of $n b S$, as results from the dispersal experiment

248 suggested that the nearest neighbors would be most important, and second-neighbor quadrats are

249 not well represented in linear transect data. Repeating the analysis including second neighbors

250 did not change the result, and second neighbors were not significant after accounting for first

251 neighbors. To compare the effect of each process shaping adult and rosette densities, we

252 predicted adult $\left(A_{t}\right)$ and rosette $\left(R_{t}\right)$ densities at time $t$ as functions of factors representing the

253 three main processes (Table 2). We conducted spatial regression analyses using the function

254 "errorsarlm" in R library "spdep" (Bivand et al. 2012), separately for adults and rosettes and for

255 two years $t$ (2010 and 2011), each with a spatially autocorrelated error term to account for

256 potential spatial autocorrelation in the residuals. To facilitate comparison among processes, all

257 transformed variables (discussed below) were standardized (mean $=0$, variance $=1$ ), and thus no

258 intercept was required. Spatial regression models were defined as follows:

$$
R_{\mathrm{t}} \sim P o p+\beta_{1} M+\beta_{2} L A I+\beta_{3} q S_{\mathrm{t}-1}+\beta_{4} n b S_{\mathrm{t}-1}+\beta_{5} A_{\mathrm{t}}+\lambda \mathbf{W}+\varepsilon
$$

$$
A_{\mathrm{t}} \sim P o p+\beta_{1} M+\beta_{2} L A I+\beta_{3} R_{\mathrm{t}-1}+\lambda \mathbf{W}+\varepsilon,
$$

where 'Pop' refers to a random population effect, $\beta$ refers to the regression coefficients

262 (slope parameter) associated with the explanatory variables (see Table 2 for the definition of

263 variables), $\lambda$ is the coefficient of the spatial error term (a significant $\lambda$ indicates significant

264 residual spatial autocorrelation), which was defined by a spatial weight matrix W (where

265 adjacent quadrats were neighbors; binary neighbor list, weights = row standardized), and $\varepsilon$ is the 
266 independent error term. Correlations among predictors were non-significant, except a moderately

267 significant correlation among $q S$ and $n b S$. To improve residual distribution, density data were

268 transformed to square roots, and quadrat-level seed production $q S$, seeds from neighbors $n b S$,

269 soil moisture $M$ and light $L A I$ to natural logarithm. Residual analyses showed that

270 transformations were successful, as the distributions of non-spatial residuals $\varepsilon$ were

271 approximately normal and variances were relatively homogeneous. The proportion of variance

272 explained by each spatial regression $\left(p s e u d o-R^{2}\right.$ ) was computed as the squared correlation of the

273 fitted values predicted from the non-spatial predictors in the model (i.e., without the spatial error

274 term) and the original transformed variable (Biswas and Wagner 2014, Biswas et al. 2014). We

275 performed all analyses in R 2.14.2 (R Development Core Team 2011).

\section{Results}

278 Spatial scale of seed dispersal

279 The lognormal model provided the best fitting dispersal kernels for A. petiolata (Table 1,

280 Fig. 2). After correcting for the radial diffusion effect, the averaged model (radial pdf) with

281 parameters $\mu=0.407$ and $\sigma=0.620$ resulted in an estimated mean seed displacement distance

282 from a point source of $1.82 \mathrm{~m}$. This means that $3.8 \%$ of seeds are expected to fall within $0.5 \mathrm{~m}$,

$28349.9 \%$ within $1.5 \mathrm{~m}$, and $79.4 \%$ within $2.5 \mathrm{~m}$. In the context of our transects with $1 \mathrm{~m}^{2}$ quadrats,

$2843.8 \%$ of seeds are expected to stay within the quadrat, $46.1 \%$ go to direct neighbor quadrat, 29.5

$285 \%$ to second neighbor, and $20.6 \%$ go beyond the second neighbor. Point source 5 showed a high

286 level of disturbance with 13 displaced seed traps. Excluding this replicate from averaging

287 resulted in a radial pdf (Fig. 2) with parameters $\mu=0.427$ and $\sigma=0.646$ and a mean

288 displacement distance of $1.89 \mathrm{~m}$. 
Biswas \& Wagner: Spatial structure of A. petiolata

\section{Spatial structure of rosettes and adults}

290 For both adults and rosettes, we found significant positive spatial autocorrelation up to

291 the second lag (i.e., $2 \mathrm{~m}$ ), except for adults in 2011, where only the first lag was significant (Fig.

292 3). In rosettes, global Moran's $I$ (which is equivalent to the first lag, $I(1))$ was $+0.59(P<0.01)$

293 in 2009, $+0.57(P<0.01)$ in 2010 and $+0.48(P<0.01)$ in 2011. In adults, global Moran's $I$ was

$294+0.66(P<0.01)$ in $2009,+0.56(P<0.01)$ in 2010 and $+0.31(P<0.01)$ in 2011. There was some

295 variation in patterns (intensity and range of autocorrelation) among the three replicate

296 populations: for rosettes, spatial autocorrelation in the first distance class was consistently

297 significant for all three populations in all three years $(2009,2010$ and 2011), whereas for adults,

298 it was significant for all three populations in 2009 and 2010 and only for one in 2011 (Online

299 Resource 2).

300

\section{Relative importance of processes}

$302 \quad$ For rosettes in $2010\left(R_{2010}\right)$, propagule pressure in terms of previous year's quadrat-level

303 seed production $\left(q S_{2009}\right)$ and seeds from neighbouring quadrats $\left(n b S_{2009}\right)$ showed significant

304 positive effects on rosette density, and same years' adult density $A_{2010}$ had a significant negative

305 effect (Table 3$)$. The standardized $\beta$ coefficients indicated that propagule pressure $(\beta=0.48$ for

$306 q S_{2009}$ and $\beta=0.26$ for $n b S_{2009}$ ) was the most important process compared to interactions among

307 life stages $\left(\beta=-0.28\right.$ for $\left.A_{2010}\right)$ and environmental filtering $(n s)$. In 2011, only propagule pressure

308 had a significant positive effect on rosette density $(\beta=0.26$ for $q S)$. In adults, previous year's

309 rosette density $R_{\mathrm{t}-1}$ was the only significant process in both years (Table 3 ). The effects of

310 environmental factors were not significant in either rosettes or in adults (Table 3), but random

311 population effects were significant. Notably, there was significant spatial autocorrelation in the

312 residuals for adult and rosette density in both years (see values of $\lambda$ in Table 3). 
Biswas \& Wagner: Spatial structure of A. petiolata

\section{Discussion}

\section{Seed dispersal and the spatial structure of rosettes and adults}

315 Based on a fitted lognormal dispersal kernel, seed dispersal of $A$. petiolata under field

316 conditions is spatially restricted with a short mean dispersal distance of $1.82 \mathrm{~m}$. The spatial

317 structure of both rosette and adult densities, as assessed by spatial autocorrelation, was

318 significant at a small spatial scale of 1-2 m, which is consistent with the results from the seed

319 dispersal experiment. Spatial regression analysis of survey data on rosette density revealed

320 propagule pressure from within the same quadrat $(\beta=0.48,0.26)$ as the most important process

321 structuring within-quadrat rosette density in both 2010 and 2011, while the importance of

322 dispersal from adjacent quadrats was confirmed for 2010 by a significant effect $(\beta=0.26)$ of

323 neighboring seed production $(n b S)$. Based on the independent evidence from the dispersal

324 experiment and the survey data, we conclude that seed dispersal is important, but occurs mostly

325 at a very small scale. Short-range dispersal may thus largely be responsible for spatial structure

326 of rosettes in the studied populations of $A$. petiolata (Fig 3).

327 Some caveats need to be considered when interpreting the results from our dispersal

328 experiment. The fact that we recovered seeds up to the maximum distance of seed traps from the

329 point sources $(4 \mathrm{~m})$, with no other potential sources within at least $6 \mathrm{~m}$, indicates that seeds may

330 travel further, and hence the full tail of the dispersal kernel is not captured in this experiment.

331 Given the estimated dispersal kernel, it is unlikely that many seeds would have dispersed by

332 gravity from sources outside our experimental plots. However, secondary dispersal by animal

333 vectors may have occurred. We noticed animal disturbance, resulting in displacement of several

334 seed traps and deposition of uprooted stalks with entire siliques attached. These problems

335 occurred mostly in one of the five replicates, and we estimated dispersal kernel both with and 


\section{Biswas \& Wagner: Spatial structure of A. petiolata}

336 without this replicate. Overall, the results provide a much needed first empirical estimate of a

337 seed dispersal kernel in $A$. petiolata under natural field conditions.

338 The overall patchiness (i.e., spatial autocorrelation) in both adult and rosette densities

339 was similar from 2009 to 2011 (Fig 3), except for a slight reduction in patchiness in adults in

340 2011. The result that both adults and rosettes showed similar degree of patchiness $(\sim 2 \mathrm{~m})$ despite

341 demographic thinning (mortality) in rosettes suggests that the legacy of seed dispersal on the

342 spatial structure of individuals, both adults and rosettes, is very strong. On the other hand, the

343 observed reduction in patchiness in adults in 2011 may not be surprising because ecological

344 processes are dynamic, and the presence of multiple processes acting at local or broader scales

345 may produce varying degrees of spatial structure over time (Levin 1992). We identified short-

346 range dispersal and the resulting propagule pressure as the key process that creates spatial

347 structure in A. petiolata density. Factors such as animal and human movement in an A. petiolata

348 patch may affect dispersal (Cavers et al. 1979) and thus spatial structure of rosettes and adults. In

349 addition and at broader spatial scales, annual variation in weather patterns, including discrete

350 climatic events such as timing of the first rain storm of a season or cold storm temperature, may

351 strongly affect demography, especially seed germination, of short-lived plants (Levine et al.

352 2011). In A. petiolata, dramatic variations in demographic parameters between sites and between

353 study years associated with environmental heterogeneity and stochasticity in weather such as rain

354 and drought have been reported (Evans et al. 2012; Biswas et al. 2014). Finally, the ongoing

355 research resulted in a considerable increase in human movement from 2009 - 2011 in our study

356 populations, which may have affected dispersal patterns and thus introduced noise in the spatial

357 structure, potentially resulting in an overall reduction of the explanatory power of the measured

358 variables from 2010 to 2011 (Table 3). 
Biswas \& Wagner: Spatial structure of A. petiolata

360

361 stages

362

363

364

365

366

367

368

369

370

371

372

373

374

375

376

377

378

379

380

381

382

383 stages

Relative importance of propagule pressure, environmental filtering and competition between life

Previous year's rosette density was the most important predictor of adult density in both years $(\beta=0.81$ in 2010 and $\beta=0.45$ in 2011 ), which implies that adult density is strongly related to propagule pressure. Similarly for rosette density, propagule pressure was the most important predictor $\left(\beta=0.48\right.$ for $q S_{2009}, 0.26$ for $\left.n b S_{2009}\right)$, though the effect was weaker in 2011

$\left(\beta=0.26\right.$ for $\left.q S_{2010}\right)$. We suspect that weakening of the effects of dispersal $(n b S)$ in 2011 , and the reduction of pseudo- $R^{2}$ from 0.58 in 2010 to 0.09 in 2011 , may be related to year-to-year variation in demographic parameters as observed in Meekins and McCarthy (2002) and in Winterer et al. (2005), variability in seed production in unmeasured neighboring quadrats, the ignoring of second neighbor quadrats as potential seeds sources, soil seed bank, or to disturbance of seed dispersal patterns resulting from the ongoing research as discussed above. However, our overall results highlight the importance of propagule pressure or colonization in shaping patterns of density in A. petiolata, and this is consistent with a general prediction of invasion ecology that propagule pressure is a key driver of biological invasion (Colautti et al. 2006).

As hypothesized, we found non-significant effects of environmental filtering for adult or rosette density (Cavers et al. 1979; Winterer et al. 2005). However, we found that negative association between life stages was the second most important process to the explanation of rosette density (Winterer et al. 2005; Bauer et al. 2010; Evans et al. 2012): same year's adults had a strong, significant negative correlation with rosette density in $2010(\beta=-0.28, P<0.01)$. In 2011, however, the life stage interaction was not significant $(P=0.73)$, which may be due to strong spatio-temporal segregation between rosettes and adults (in 2010) followed by a holefilling effect (2011), i.e., a phase when rosettes and adults mix (Meekins and McCarthy 2002; Winterer et al. 2005; Bauer et al. 2010). Although competitive interactions between adult and 


\section{Biswas \& Wagner: Spatial structure of A. petiolata}

384 rosette life stages of $A$. petiolata has been reported earlier (Meekins and McCarthy 2002,

385 Winterer et al. 2005; Bauer et al. 2010; Evans et al. 2012), we are not able to determine a causal

386 role of competition between life-stages from this observational data, because negative correlation

387 between the life-stages could also be driven by temporal variation in density-dependent seed

388 production (i.e., areas with high adult densities in 2010 likely had low seed production in 2009 ,

389 and thus low rosette densities in 2010). While our spatial regression accounts for some sources of

390 seed production (within the quadrat and the two neighboring quadrats), substantial seed rain is

391 likely to come from adjacent quadrats that remains unaccounted. Further research is required to

392 determine the causality underlying negative association between adult and rosette density; and if

393 competition prevails, the conditions for strong competition between life stages and how the

394 strength of competition changes from seed germination in spring to seed shed in summer, so as

395 to identify optimal timing for management interventions.

396 Nevertheless, we found significant spatial autocorrelation in the residuals $(\lambda)$ in both

397 adult and rosette density for both 2010 and 2011, which may indicate the presence of

398 unaccounted processes. Density and spatial structure in a population may be generated through

399 demographic processes (Powell 1990), and based on existing literature on A. petiolata, density

400 dependence or herbivory are likely confounding processes (Davis et al. 2006; Evans et al. 2012;

401 Biswas and Wagner 2014; Biswas et al. 2014). Further research should thus include

402 quantification of these processes.

404 Implications for management

405 Our results have implications for the life stage to target and the timing of management in

406 controlling this species. First, our assessment of the relative importance of processes revealed 407 that propagule pressure is the strongest factor governing rosette density, i.e., rosettes grow where 


\section{Biswas \& Wagner: Spatial structure of A. petiolata}

408 seeds land, and adult density is governed by rosette density, i.e., adults are still living primarily

409 where the seeds landed despite thinning effects. The adult life stage should be targeted for

410 management to cut off propagule supply and thus regulate the population. Interestingly, we also

411 found that adult density was negatively correlated with the density of rosettes; this result

412 suggests a benefit of late removal of adults to suppress rosette survival, though adults should be

413 removed or their inflorescences cut before seeds are developed. However, this strategy should be

414 further tested over multiple years in replicate sites to account for the potential confounding by a

415 cyclical alternation of adult- and rosette-dominated years and a legacy effect of the soil seed

416 bank.

417 To conclude, the first available estimate of $A$. petiolata mean dispersal distance under

418 field conditions will provide important guidance for empirical studies and computer simulation

419 modeling aimed at developing optimal management strategies. Overall, the results from this

420 study together with earlier studies on $A$. petiolata suggest that rosette density is positively related

421 to propagule pressure but negatively related to adult density (Meekins and McCarthy 2002;

422 Winterer et al. 2005; Bauer et al. 2010; Evans et al. 2012). In contrast, fine-scale variation in

423 environmental site conditions does not seem to matter for structuring this species. Our results

424 suggest that the adult life stage should be targeted for management, the strong negative effect of

425 adult density on rosette density suggests removing adults later, before seed shed, rather than

426 early in spring, to benefit from this intraspecific interaction.

\section{Acknowledgements}

429 The study was supported by a NSERC discovery grant to HHW. We thank Art Weis for 430 providing the design and offering some of his seed-traps, Daz Kambo, Adrian DiFederico and 431 Zangeetha Perinathan for assisting in field or laboratory works, and Marie-Josée Fortin, Peter 
432 Kotanen, Benjamin Gilbert, Mark Vellend, Lindsay Turnbull, Richard Lankau and two

433 anonymous reviewers for comments or discussion on earlier versions of this manuscript. This is

434 a publication of Koffler Scientific Reserve at Jokers Hill.

\section{References}

437 Anderson RC, Dhillon SS, Kelley TM (1996) Aspects of the ecology of an invasive plant, garlic 438 mustard (Alliaria petiolata), in central Illinois. Restoration Ecology 4: 181-191

439 Bauer JT, Anderson RC, Anderson MR (2010) Competitive interactions among first-year and 440 second-year plants of the invasive, biennial garlic mustard (Alliaria petiolata) and native 441 ground layer vegetation. Restor. Ecol. 18:720-728

442 Biswas SR, Kotanen PM, Kambo D, Wagner HH (2014) Context-dependent patterns, 443 determinants and demographic consequences of herbivory in an invasive species. Biological 444 Invasions DOI: $10.1007 / \mathrm{s} 10530-014-0715-0$

445 Biswas SR, Wagner HH (2012) Landscape contrast: a solution to hidden assumptions in the 446 metacommunity concept? Landscape Ecology 27: 621-631

447 Biswas SR, Wagner HH (2014) A temporal dimension to the stress gradient hypothesis for 448 intraspecific interactions. Oikos DOI:10.111/oik.00878

449 Bivand R, Altman M, Anselin L, Assunção R, Berke O, Bernat A, Blanchet G, Blankmeyer E, 450 Carvalho M, Christensen B, Chun Y, Dormann C, Dray S, Halbersma R, Krainski E, 451 Legendre P, Lewin-Koh N, Li H, Ma J, Millo G, Mueller W, Ono H, Peres-Neto P, Piras G, 452 Reder M, Tiefelsdorf M, Yu D (2012) spdep: Spatial dependence: weighting schemes, 453 statistics and models. R package version 0.5-46/r430. http://R-Forge.R454 project.org/projects/spdep/ 
Biswas \& Wagner: Spatial structure of A. petiolata

455 Bullock JM, Clarke RT (2000) Long distance seed dispersal by wind: measuring and modelling

456 the tail of the curve. Oecologia 124: 506-521

457 Cavers P, Heagy M, Kokron R (1979) The biology of Canadian weeds. 35. Alliaria petiolata (M.

458 Bieb.) Cavara and Grande. Canadian Journal of Plant Science 59: 217-229

459 Clobert J, Danchin E, Dhondt AA, Nichols JD (2001) Dispersal. Oxford University Press, UK

460 Colautti RI, Grigorovich IA, MacIsaac HJ (2006) Propagule pressure: a null model for biological

$461 \quad$ invasions. Biological Invasions 8: 1023-1037

462 Cottenie K (2005) Integrating environmental and spatial processes in ecological community

463 dynamics. Ecology Letters 8: 1175-1182.

464 Cruden RW, McClain AM, Shrivastava G (1996) Pollination biology and breeding system of

465 Alliaria petiolata (Brassicacea). Bulletin of the Torrey Botanical Club 123: 273-280

466 Dale MRT (1999) Spatial pattern analysis in plant ecology. Cambridge University Press,

467 Cambridge, UK

468 Davis AS, Landis DA, Nuzzo V, Blossey B, Gerber E, Hinz HL (2006) Demographic models

469 inform selection of biocontrol agents for garlic mustard (Alliaria petiolata). Ecological

$470 \quad$ Applications 16: 2399-2410

471 Dormann CF, McPherson J, Araújo MB, Bivand R, Bolliger J, Carl G, Davies RG, Hirzel A, Jetz

472 W, Kissling WD, Kühn I, Ohlemüller R, Peres-Neto P, Reineking B, Schröder B, Schurr FM,

473 Wilson R (2007) Methods to account for spatial autocorrelation in the analysis of

474 distributional species data: a review. Ecography 30: 609-628.

475 Dray S, Pellissier R, Couteron P, Fortin MJ, Legendre P, Peres-Neto P, Bellier E, Bivand R,

476 Blanchet FG, Caceres M, Dufour AB, Heegaard E, Jombart T, Munoz F, Oksanen J,

477 Thioulouse J, Wagner HH (2012) Community ecology in the age of multivariate multiscale

$478 \quad$ spatial analysis. Ecological Monographs 82: 257-275 
Biswas \& Wagner: Spatial structure of A. petiolata

479 Evans JA, Davis AS, Raghu R, Ragavendran A, Landis DA, Schemske DW (2012) The

480 importance of space, time, and stochasticity to the demography and management of Alliaria

$481 \quad$ petiolata. Ecological Applications 22: 1497-1511

482 Fortin MJ, Dale MRT (2005) Spatial Analysis: A Guide for Ecologists. Cambridge University $483 \quad$ Press

484 Fortin M-J, James PMA, MacKenzie A, Melles SJ, Rayfield B (2012) Spatial statistics, spatial 485 regression, and graph theory in ecology. Spatial Stat 1:100-109

486 Gilpin ME, Hanski I (1991) Metapopulation dynamics: empirical and theoretical investigations.

487 Academic press, London

488 Hewitt JE, Legendre P, McArdle BH, Thrush SF, Bellehumeur C, Lawrie SM (1997) Identifying

489 relationships between adult and juvenile bivalves at different spatial scales. Journal of $490 \quad$ Experimental Marine Biology and Ecology 216: 77-98

491 Holt RD, Hoopes MF (2005) Food web dynamics in a metacommunity context. In: Holyoak M,

492 Leibold MA, Holt RD (eds) Metacommunities: Spatial Dynamics and Ecological

493 Communities. University of Chicago Press, Chicago and London, pp. 68-93

494 Jones O, Maillardet R, Robinson A, Borovkova O, Carnie C (2009) Introduction to Scientific

495 Programming and Simulation Using R. Taylor and Franchis Group, LLC, USA

496 Jones O, Maillardet R, Robinson A, Borovkova O, Carnie C (2012) spuRs: Functions and

497 Datasets for "Introduction to Scientific Programming and Simulation Using R" R package $498 \quad$ version 1.0 .5

499 Legendre P (1993) Spatial autocorrelation: trouble or new paradigm? Ecology 74: 1659-1673

500 Legendre P, Legendre L (1998) Numerical Ecology. Elsevier 


\section{Biswas \& Wagner: Spatial structure of A. petiolata}

501 Leibold MA, Holyoak M, Mouquet N, Amarasekare P, Chase JM, Hoopes MF, Holt RD, Shurin

502 JB, Law R, Tilman D, Loreau M, Gonzalez A (2004) The metacommunity concept: a

503 framework for multiscale-community ecology. Ecology Letters 7: 601-613

504 Levin SA (1992) The problem of pattern and scale in ecology: the Robert H. MacArthur Award

$505 \quad$ Lecture. Ecology 73: 1943-1967

506 Levine JM, McEachern AK, Cowan C (2011) Seasonal timing of first rain storms affects rare

507 plant population dynamics. Ecology 92: 2236-224

508 Lockwood J, Cassey P, Blackburn T (2005) The role of propagule pressure in explaining species

509 invasions. Trends in Ecology and Evolution 20: 223-228

510 Luken JO, Thieret JW (1997) Assessment and management of plant invasions. Springer series on

511 environmental management. New York: Springer. pp117

512 Malkinson D, Jeltsch F (2007) Intraspecific facilitation: a missing process along increasing stress

513 gradient - insights from simulated shrub populations. Ecography 30: 339-348

514 McCann KS, Rasmussen JB, Umbanhowar J (2005) The dynamics of spatially coupled food

$515 \quad$ webs. Ecology Letter 8: 513-523

516 McIntire EJB, Fajardo A (2009) Beyond description: the active and effective way to infer

517 processes from spatial patterns. Ecology 90: 46-56

518 Meekins JF, McCarthy BC (2001) Effect of environmental variation on the invasive success of a

519 nonindigenous forest herb. Ecological Applications 11: 1336-1347

520 Moran PAP (1948) The interpretation of statistical maps. Journal of Royal Statistics Society B

$521 \quad$ (Methodological) 10: 243-251

522 Nathan R, Muller-Landau HC (2000) Spatial patterns of seed dispersal, their determinants and 523 consequences for recruitment. Trends in Ecology and Evolution 15: 278-285 
Biswas \& Wagner: Spatial structure of A. petiolata

524 Pielou EC (1960) A single mechanism to account for regular, random and aggregated

525 populations. Journal of Ecology 69: 575-584

526 Powell RD (1990) The role of spatial pattern in the population biology of Centaura diffusa.

$527 \quad$ Journal of Ecology 78: 374-388

528 R Development Core Team (2011) R: A language and environment for statistical computing.

$529 \quad$ Viena: R Foundation for Statistical Computing.

530 Rodgers VL, Stinson KA, Finzi AC (2008) Ready or not, garlic mustard is moving in: Alliaria

531 petiolata as a member of eastern north American forests. BioScience 58(5): 426-436

532 Schlup B, Wagner HH (2008) Effects of the study design and analysis on the spatial community

533 structure detected by multiscale ordination. Journal of Vegetation Science 19: 621-632

534 Seabloom EW, Bjornstad ON, Bolker BM, Reichman OJ (2005) Spatial signature of

535 environmental heterogeneity, dispersal, and competition in successional grasslands.

$536 \quad$ Ecological Monographs 75: 199-214

537 Venables WN, Ripley BD (2002) Modern Applied Statistics with S. Fourth Edition. Springer, $538 \quad$ New York

539 Wagner HH, Fortin MJ (2005) Spatial analysis of landscapes: concepts and statistics. Ecology $540 \quad 86: 1975-1987$

541 Williamson M (1996) Biological Invasions. Chapman Hall, London UK, 244 pp

542 Winterer J, Walsh MC, Poddar M, Brennan JW, Primak SM (2005) Spatial and temporal

543 segregation of juvenile and mature garlic mustard plants (Alliaria petiolata) in a central

544 pensylvania woodland. The American Midland Naturalist 153: 209-216

545 


\section{Table 1}

547 Fits of the dispersal kernels models (transect probability density functions) for Alliaria petiolata;

548 models are ranked on the basis of the AICc.

\begin{tabular}{|c|c|c|c|c|c|c|c|}
\hline \multirow[b]{2}{*}{ Function } & \multirow[b]{2}{*}{ Model } & \multicolumn{5}{|c|}{ AICc of replicate point sources $(1-5)$} & \multirow[b]{2}{*}{ Rank } \\
\hline & & 1 & 2 & 3 & 4 & $5 *$ & \\
\hline Lognormal & $f(x)=\frac{1}{x \cdot \sigma \sqrt{2 \pi}} e^{-\frac{(\ln (x)-\mu)^{2}}{2 \sigma^{2}}}$ & 84.0 & 85.8 & 61.6 & 73.1 & 127.3 & 1 \\
\hline Weibull & $f(x)=\left(\begin{array}{ll}\frac{k}{\lambda}\left(\frac{x}{\lambda}\right) e^{-\left(\frac{x}{\lambda}\right)^{k}} & x \geq 0 \\
0 & x \leq 0\end{array}\right)$ & 97.6 & 104.1 & 63.0 & 78.8 & 136.0 & 2 \\
\hline Exponential & $f(x)=\lambda e^{-\lambda x}$ & 108.5 & 113.0 & 70.7 & 83.0 & 180.7 & 3 \\
\hline Half-normal & $f(x)=\frac{\sqrt{2}}{\sigma \sqrt{\pi}} e^{-\frac{x^{2}}{2 \sigma^{2}}} x>0$ & 121.9 & 136.6 & 69.5 & 94 & 151.2 & 4 \\
\hline
\end{tabular}

$549 *$ A large number of seed traps were displaced (by animals) in this replicate.

550 
Biswas \& Wagner: Spatial structure of A. petiolata

\section{Table 2}

552 Ecological processes and measured variables known to be relevant to processes

\begin{tabular}{|c|c|c|}
\hline \multirow{2}{*}{$\begin{array}{l}\text { Ecological } \\
\text { processes }\end{array}$} & \multicolumn{2}{|c|}{ Variables hypothesized to be associated with each process } \\
\hline & Rosette density $\left(\mathrm{R}_{\mathrm{t}}\right)$ & Adult density $\left(\mathrm{A}_{\mathrm{t}}\right)$ \\
\hline $\begin{array}{l}\text { Environmental } \\
\text { filtering }\end{array}$ & $\begin{array}{l}\text { - } \text { Soil moisture (M), } \\
\text { - } \quad \text { Light (LAI) }\end{array}$ & $\begin{array}{l}\text { - } \quad \text { Soil moisture }(\mathrm{M}) \text {, } \\
\text { - } \quad \text { Light (LAI) }\end{array}$ \\
\hline Propagule pressure & $\begin{array}{l}\text { - Quadrat-level seed production }\left(\mathrm{qS}_{\mathrm{t}-1}\right) \text {, } \\
\text { - Neighboring seed production }\left(\mathrm{nbS}_{\mathrm{t}-1}\right)\end{array}$ & - $\quad$ Rosette density $\left(\mathrm{R}_{\mathrm{t}-1}\right)$ \\
\hline Biotic interactions & - $\quad$ Adult density $\left(\mathrm{A}_{\mathrm{t}}\right)$ & - \\
\hline
\end{tabular}




\section{Table 3}

556 Parameter estimates from spatial regression predicting rosette $R_{\mathrm{t}}$ and adult density $A_{\mathrm{t}}$ as a

557 function of environmental filtering, propagule pressure and life-stage interactions.

\begin{tabular}{|c|c|c|c|c|c|c|}
\hline Response & Processes & Factor & Estimate & SE & $\mathrm{Z}$ & $\begin{array}{c}\text { Model } \\
\text { diagnostics } \\
\end{array}$ \\
\hline \multirow{8}{*}{ Rosettes $_{2010}$} & \multirow{3}{*}{$\begin{array}{l}\text { Random } \\
\text { population } \\
\text { effects }\end{array}$} & Pop 1 & 0.438 & 0.116 & 3.763 & \\
\hline & & Pop 2 & -0.536 & 0.145 & -3.690 & \\
\hline & & Pop 3 & -0.081 & 0.110 & -0.742 & \\
\hline & \multirow{2}{*}{$\begin{array}{l}\text { Environmental } \\
\text { filtering }\end{array}$} & Soil moisture & -0.005 & 0.053 & -0.104 & pseudo- $R^{2}=0.58$ \\
\hline & & Light & -0.030 & 0.048 & -0.630 & $\lambda=\mathbf{0 . 3 9 9}$ \\
\hline & \multirow[t]{2}{*}{$\begin{array}{l}\text { Propagule } \\
\text { pressure }\end{array}$} & $\begin{array}{l}\text { Quadrat-level } \\
\text { seed } \\
\text { production }_{2009}\end{array}$ & 0.489 & 0.057 & 8.533 & $\mathrm{AIC}=339.73$ \\
\hline & & $\begin{array}{l}\text { Seed from } \\
\text { neighbor } 2009\end{array}$ & 0.264 & 0.059 & 4.411 & \\
\hline & $\begin{array}{l}\text { Life-stage } \\
\text { interactions }\end{array}$ & Adults $_{2010}$ & -0.285 & 0.057 & -4.989 & \\
\hline \multirow{6}{*}{ Adults 2010} & \multirow{3}{*}{$\begin{array}{l}\text { Random } \\
\text { population } \\
\text { effects }\end{array}$} & Pop 1 & -0.490 & 0.083 & -5.891 & \\
\hline & & Pop 2 & 0.485 & 0.105 & 4.623 & \\
\hline & & Pop 3 & 0.159 & 0.080 & 1.976 & pseudo- $R^{2}=0.76$ \\
\hline & \multirow{2}{*}{$\begin{array}{l}\text { Environmental } \\
\text { filtering }\end{array}$} & Soil moisture & 0.003 & 0.039 & 0.076 & $\lambda=\mathbf{0 . 3 8 0}$ \\
\hline & & Light & -0.038 & 0.036 & -1.050 & $\mathrm{AIC}=233.62$ \\
\hline & Rosettes & Rosettes $_{2009}$ & 0.819 & 0.040 & 20.032 & \\
\hline \multirow{4}{*}{ Rosettes $_{2011}$} & \multirow{3}{*}{$\begin{array}{l}\text { Random } \\
\text { population } \\
\text { effects }\end{array}$} & Pop 1 & 0.088 & 0.194 & 0.452 & \\
\hline & & Pop 2 & -0.078 & 0.225 & -0.346 & \\
\hline & & Pop 3 & -0.057 & 0.182 & -0.314 & \\
\hline & Environmental & Soil moisture & -0.086 & 0.074 & -1.158 & pseudo- $R^{2}=0.09$ \\
\hline
\end{tabular}


Biswas \& Wagner: Spatial structure of A. petiolata

\begin{tabular}{|c|c|c|c|c|c|c|}
\hline Response & Processes & Factor & Estimate & SE & Z & $\begin{array}{c}\text { Model } \\
\text { diagnostics }\end{array}$ \\
\hline & filtering & Light & 0.015 & 0.067 & 0.234 & $\lambda=\mathbf{0 . 4 7 6}$ \\
\hline & $\begin{array}{l}\text { Propagule } \\
\text { pressure }\end{array}$ & $\begin{array}{l}\text { Quadrat-level } \\
\text { seed } \\
\text { production }_{2010}\end{array}$ & 0.265 & 0.076 & 3.468 & $\mathrm{AIC}=463.8$ \\
\hline & & $\begin{array}{l}\text { Seed from } \\
\text { neighbor }_{2010}\end{array}$ & 0.009 & 0.084 & 0.108 & \\
\hline & $\begin{array}{l}\text { Life-stage } \\
\text { interactions }\end{array}$ & Adults $_{2011}$ & 0.025 & 0.077 & 0.334 & \\
\hline \multirow{6}{*}{ Adults2011 } & \multirow{3}{*}{$\begin{array}{l}\text { Random } \\
\text { population } \\
\text { effects }\end{array}$} & Pop 1 & 0.427 & 0.110 & 3.860 & pseudo- $R^{2}=0.49$ \\
\hline & & Pop2 & 0.311 & 0.138 & 2.251 & $\lambda=0.216$ \\
\hline & & Pop3 & -0.597 & 0.102 & -5.811 & $\mathrm{AIC}=398.41$ \\
\hline & \multirow{2}{*}{$\begin{array}{l}\text { Environmental } \\
\text { filtering }\end{array}$} & Soil moisture & 0.007 & 0.058 & 0.124 & \\
\hline & & Light & 0.044 & 0.056 & 0.792 & \\
\hline & Rosettes & Rosettes $_{2010}$ & 0.455 & 0.063 & 7.164 & \\
\hline
\end{tabular}

$558 \mathrm{SE}=$ standard error; $Z=Z$-score; $\uparrow$ significant $(\alpha=0.05)$ values are shown in bold faces; $\downarrow \lambda=$

559 coefficient of the spatial error term; $A I C=$ Akaike Information Criteria 


\section{$560 \quad$ Figure legends}

561 Fig. 1 Design of a seed trap set ( $a$ ) showing its parts, the base (b), the bottom netting $(c)$, and

562 seed trap placement in the field $(d)$. Seed traps were placed $0.5 \mathrm{~m}$ apart, up to $4 \mathrm{~m}$ from point

563 source $(e)$. Increasing number of seed traps were placed as the distance from point source

564 increased $(f)$.

565

566 Fig. 2 Seed shadows (a-e) and estimated seed dispersal kernels $(f)$ in Alliaria petiolata for five

567 point sources (= replicates). For each point source, each bar represents the average number of

568 seeds per trap per distance class. In $f$, the transect pdf and the radial pdf are the average dispersal

569 kernel $(n=5)$ before and after correcting for the radial diffusion effect. The dotted lines (in $f)$

570 indicates transect and radial pdfs, the average dispersal kernels $(n=4)$ without point source 5 .

571

572 Fig. 3 Moran's I correlograms showing spatial structure of rosettes (left) and adults (right) of

573 Alliaria petiolata averaged over all three populations in 2009 (top), 2010 (center) and 2011

574 (bottom). A filled circle in each lag indicates statistically significant autocorrelation following a

575 progressive Bonferroni correction (Hewit et al. 1997). 

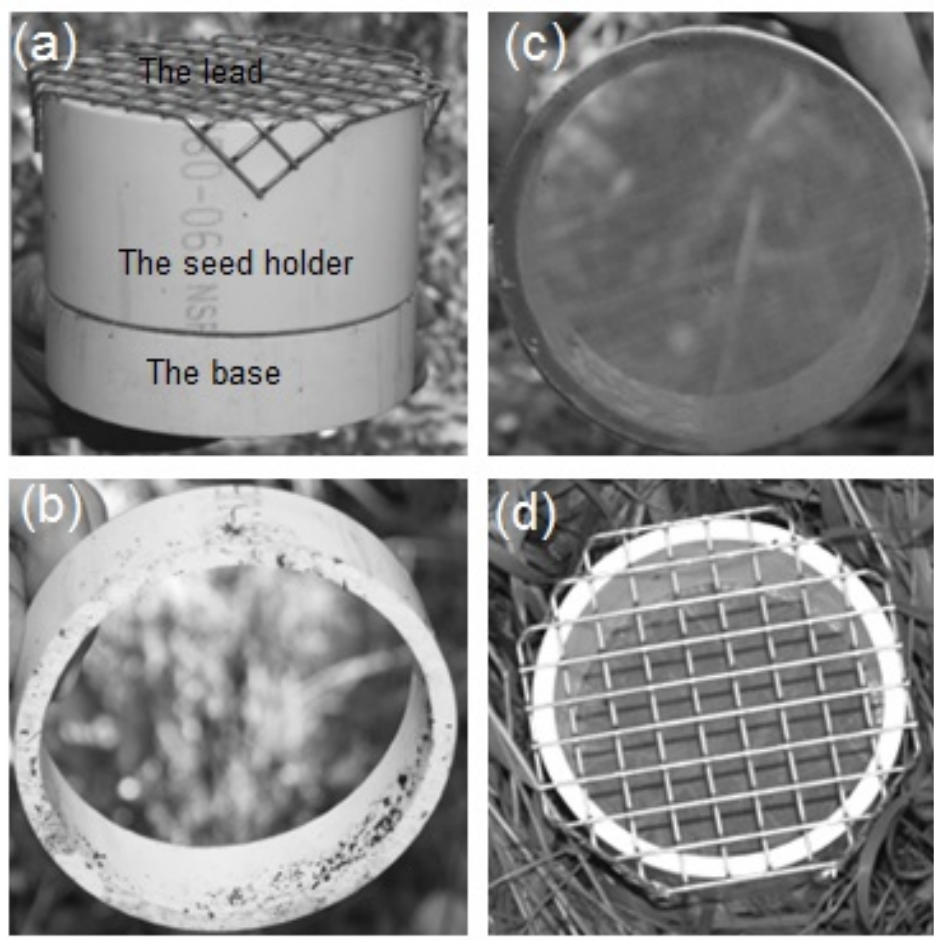

579

580

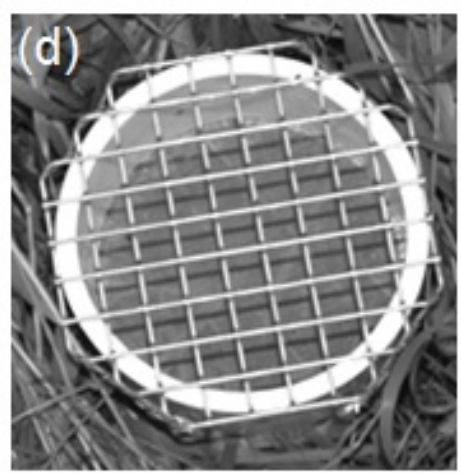

Fig. 1 (e)

point source Q seed trap
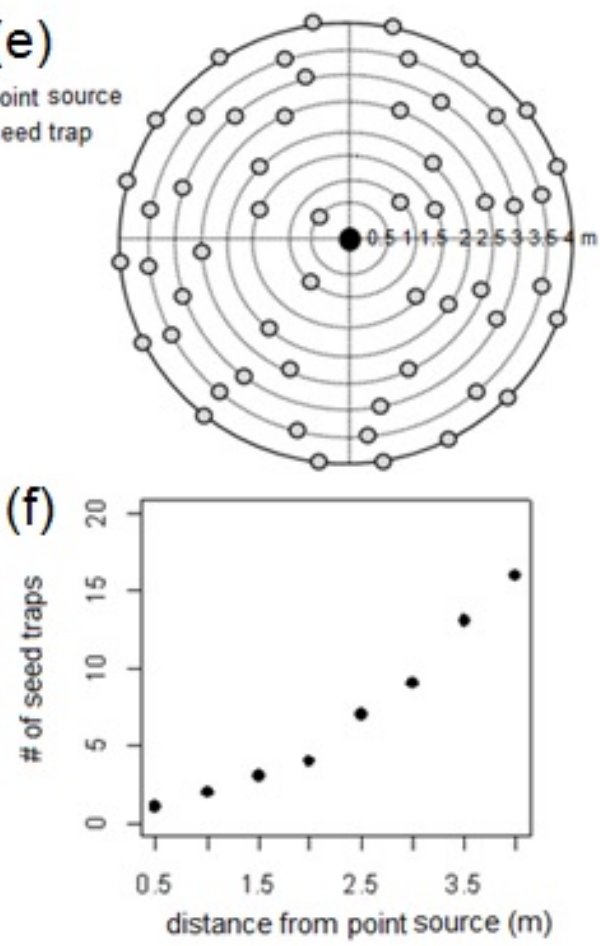
5

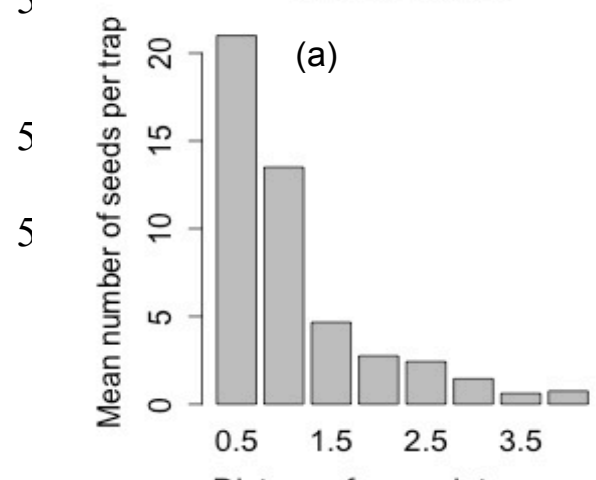

Distance from point source

Point source 4

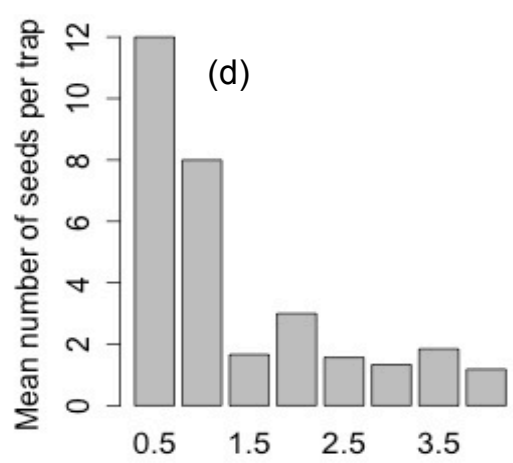

Distance from point source
Point source 2

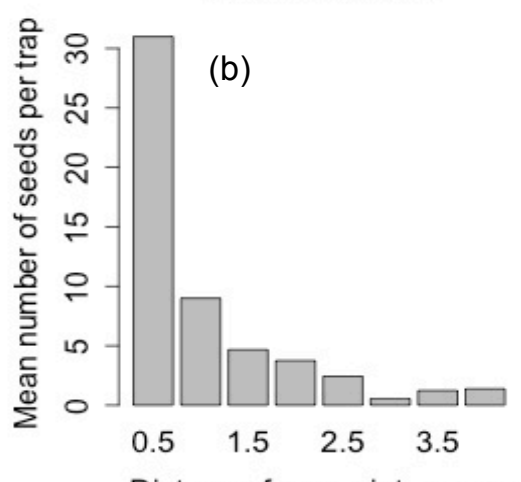

Distance from point source

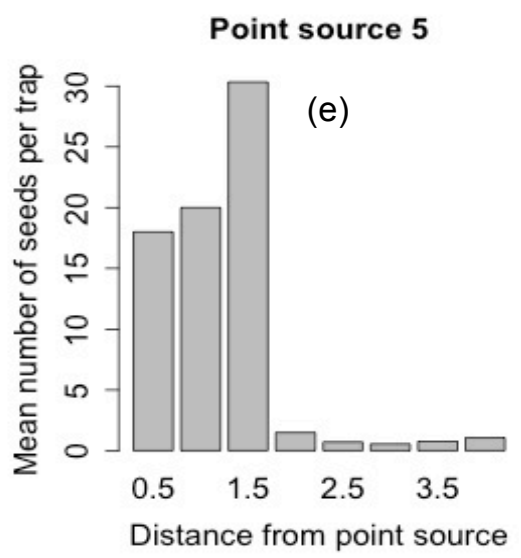

Point source 3

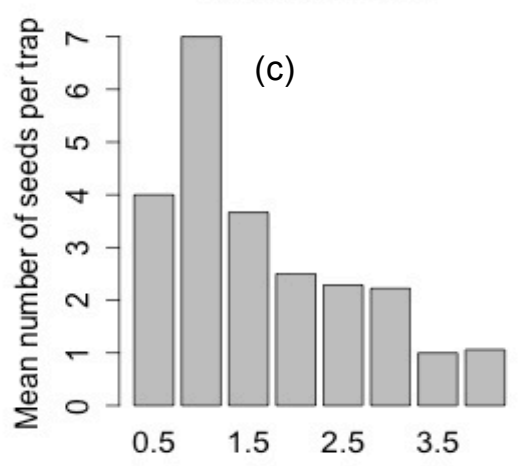

Distance from point source

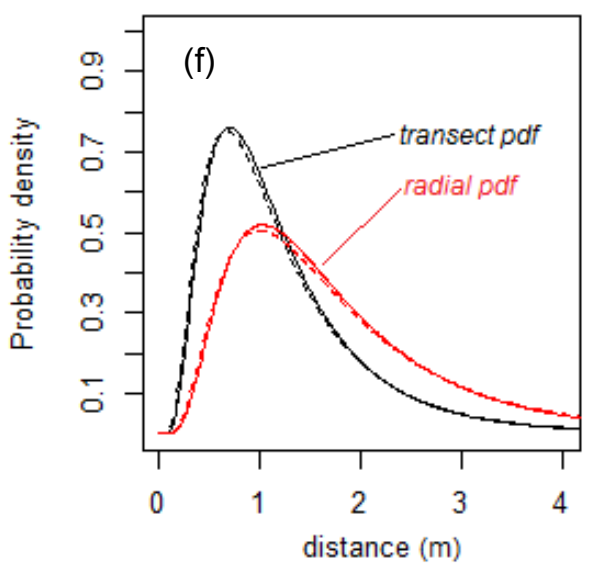


Biswas \& Wagner: Spatial structure of A. petiolata

(a) Rosette
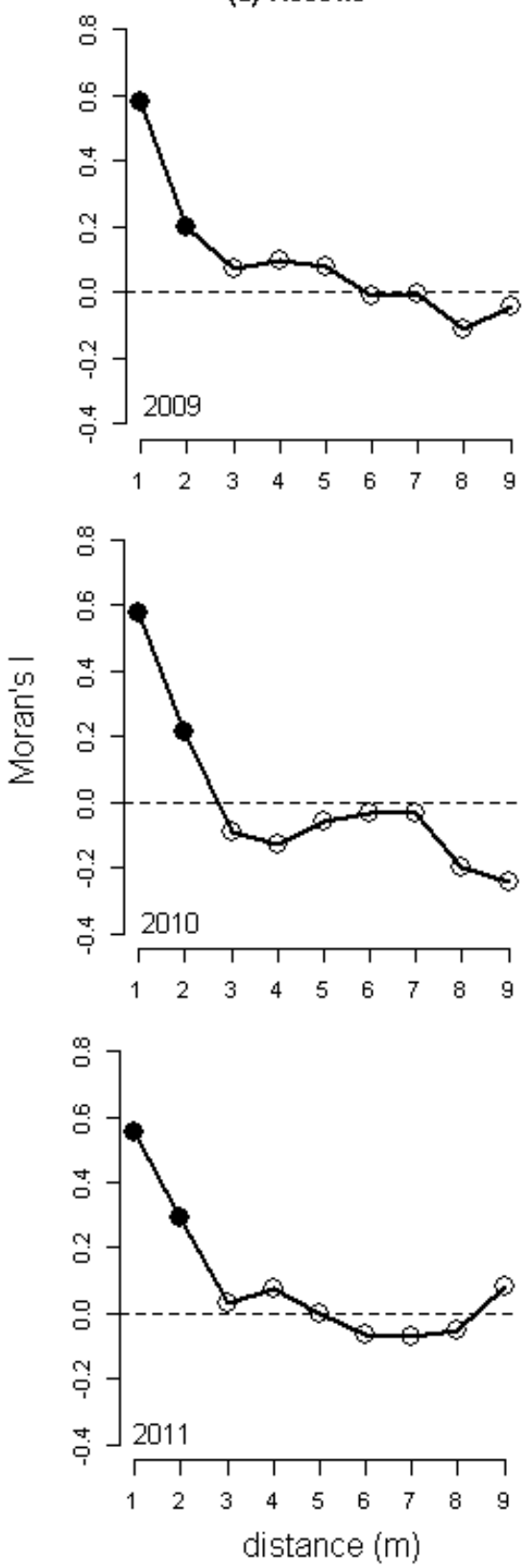

(b) Adult
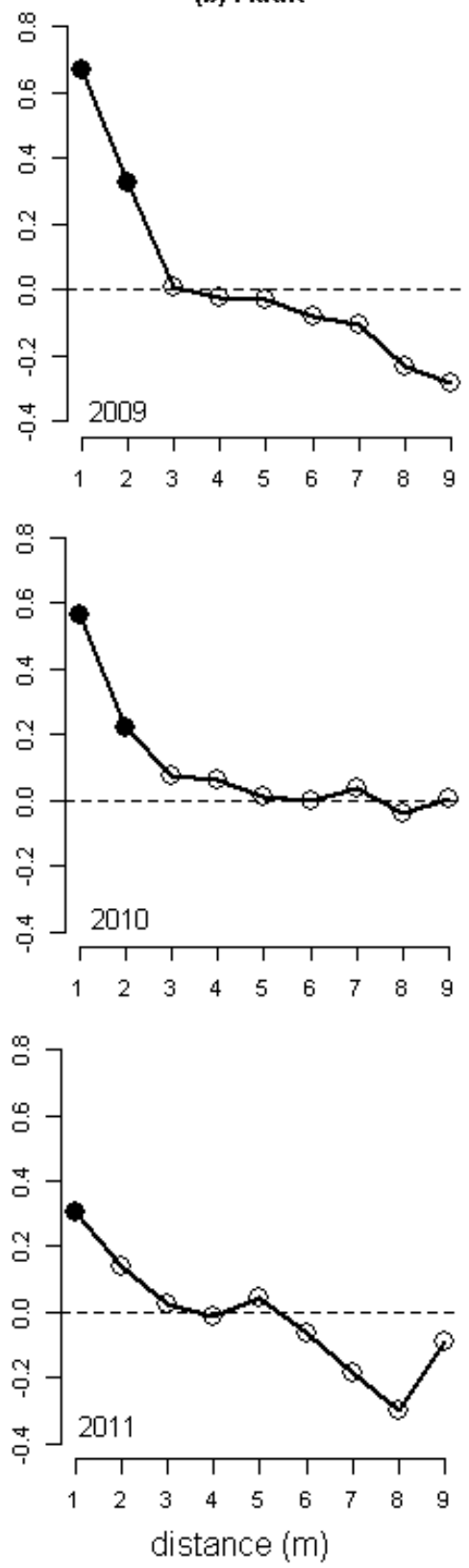
Biswas \& Wagner: Spatial structure of A. petiolata

590 Online Resource 1:

591

592 Patches of Alliaria petiolata after winter snowmelt - an example of spatial structure in the

593 studied populations. The inset shows sampling design illustrating layout of transects and

594 quadrats.

595

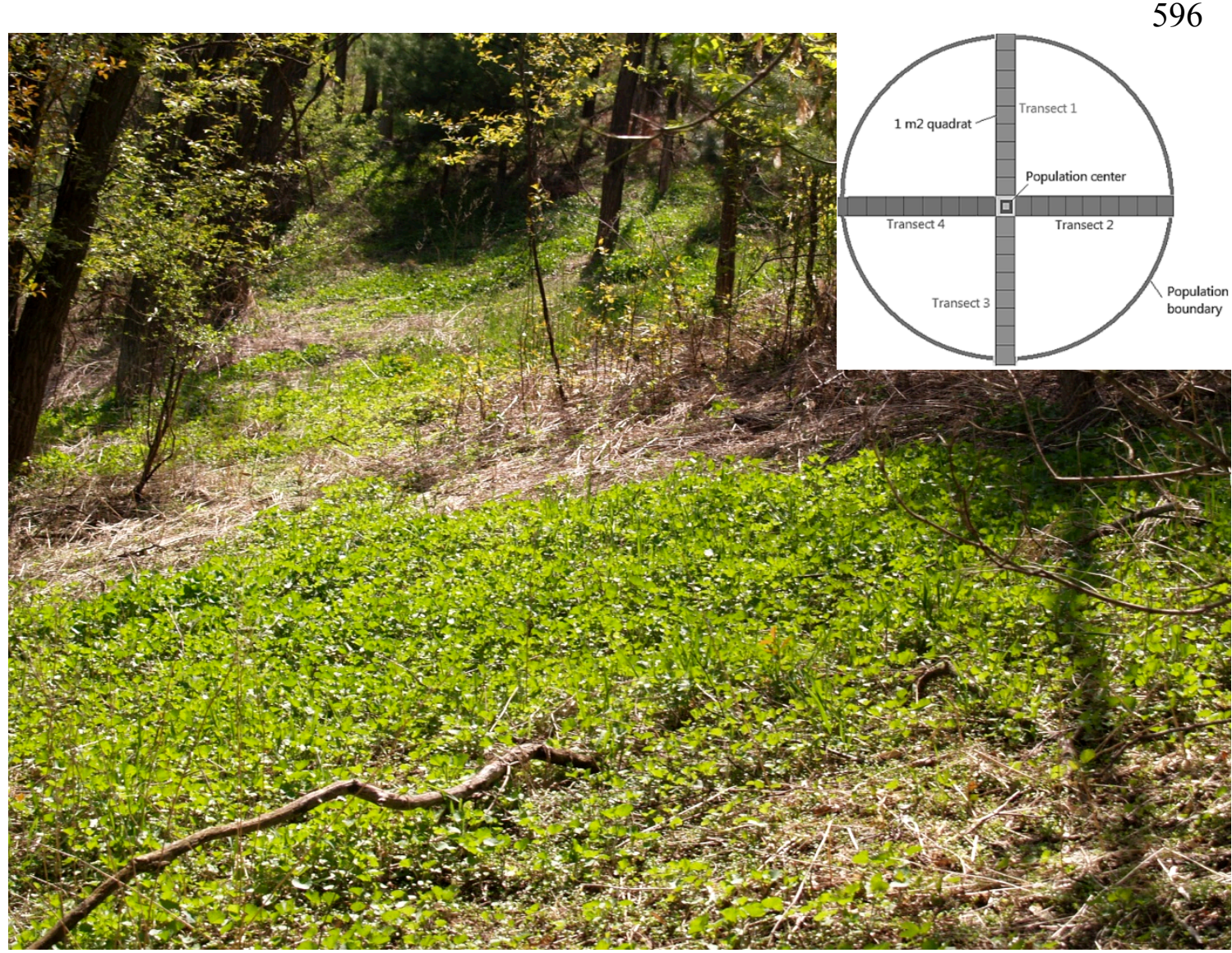


597

598

599

600

601

602

603

604

605

606

607

608

609

\section{Online Resource 2:}

Population-wise spatial correlograms for rosettes and adults for yrs. 2009-2011. A filled circle in each lag indicates statistically significant autocorrelation following a progressive Bonferroni correction (Hewit et al. 1997).
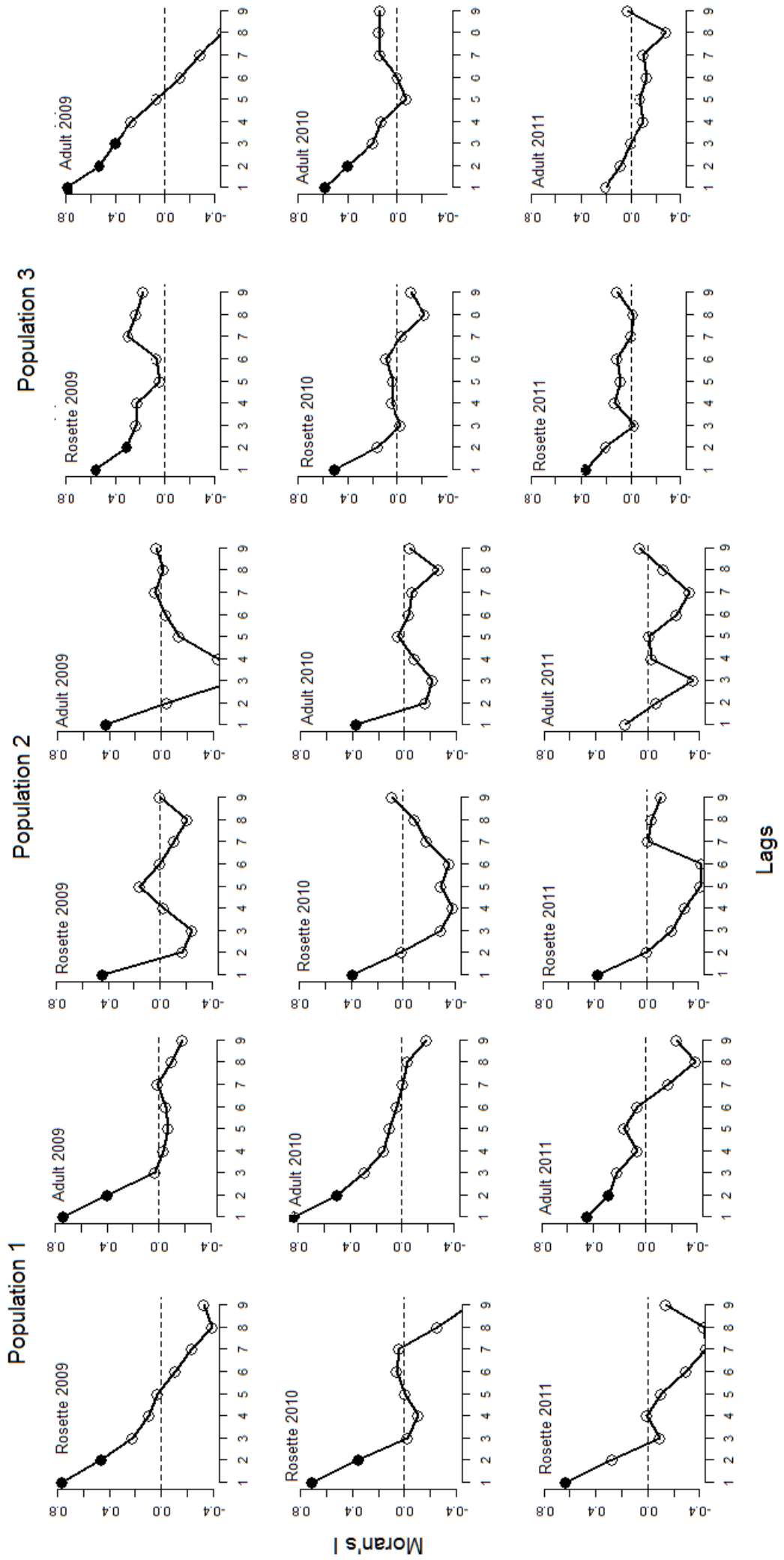